Research Article

\title{
Correlation of serum lithium levels and thyroid function tests in subjects of bipolar affective disorder: a prospective hospital-based study
}

\author{
M. S. Manjuprasad, Padmaja Udaykumar*, D. S. Maitreyee, Shreya Hegde
}

\begin{abstract}
Department of Pharmacology, Father Muller Medical College, Kankanady, Mangalore, Karnataka, India
\end{abstract}

Received: 23 November 2014 Accepted: 16 December 2014

\section{*Correspondence to:}

Dr. Padmaja Udaykumar, Email: padmajaudaykumar@ gmail.com

Copyright: (C) the author(s), publisher and licensee Medip Academy. This is an openaccess article distributed under the terms of the Creative Commons Attribution NonCommercial License, which permits unrestricted noncommercial use, distribution, and reproduction in any medium, provided the original work is properly cited.

\begin{abstract}
Background: Lithium is used in the prophylaxis of long-term therapy of bipolar affective disorder (BPAD) as a mood-stabilizing agent. Thyroid function abnormality is very commonly seen adverse effect, more common in females than males. This study aimed to correlate lithium levels and thyroid function abnormalities associated with it.

Methods: Evaluation of medical records of 150 patients in Father Muller Medical College with BPAD, who were treated for 6 months with lithium, carried out from February, 122014 to July, 20 2014. Serum lithium levels done by ion selective electrode method in ilyte analyzer and thyroid function test (TFT) by electrochemiluminescence. Data are analyzed by Karl Pearson correlation coefficient. Results: Correlation of lithium levels and TFT in BPAD patients according to Karl Pearson correlation coefficient was negative with significant $\mathrm{p}<0.002$. Among 150 enrolled candidates, $52(34.67 \%)$ were females and $98(65.4 \%)$ were males, 4\% (6) patients ( 3 males and 3 females) had thyroid stimulating hormone (TSH) value $<0.27$ with an average lithium value of $1.35 \mathrm{mEq} / \mathrm{L}, 6 \%$ (9) patients $(5$ males and 4 females) had TSH value $>4.2$ with an average lithium levels of $0.44 \mathrm{mEq} / \mathrm{L}$ and $90 \%$ of the patients with an average lithium levels $0.66 \mathrm{mEq} / \mathrm{L}$ had no thyroid function abnormalities.

Conclusions: As already known, Lithium is a drug of narrow therapeutic index and females are more prone for thyroid function abnormalities. Appropriate monitoring of serum lithium levels will aid in necessary dose adjustment and ensure proper utilization of drug.
\end{abstract}

Keywords: Bipolar affective disorder, Hyperthyroidism, Hypothyroidism, Lithium

\section{INTRODUCTION}

Bipolar affective disorder (BPAD) also known as manicdepressive illness is a brain disorder that causes unusual shifts in mood, energy, activity levels, and the ability to carry out day to day tasks. Proper treatment helps many people with bipolar disorder to gain better control of their mood swings and related symptoms. People with bipolar disorder are at higher risk for thyroid disease, migraine headaches, heart disease, diabetes, obesity, and other physical illnesses. ${ }^{1}$ Bipolar disorder often appears in the late teens or early adult years. At least half of all cases start before the age of 25 years. $^{2}$

Lithium, used in the prophylaxis of BPAD reduces the severity and frequency of mania and also been shown to reduce suicidal risk and short-term mortality. ${ }^{3}$ In spite of its efficacy, its use is associated with a number of shortcomings which include narrow therapeutic index, cardiac toxicity, renal tubular dysfunction, and endocrinopathies such as hypothyroidism, hyperthyroidism, hyperparathyroidism, hyperglycemia, and nephrogenic diabetes insipidus. It was also found that thyroid function abnormalities were more common in females than males. ${ }^{4}$ Lithium exerts its effects through multiple mechanisms which include inositol depletion as a consequence of which there is increased signaling within the cells, ${ }^{5}$ induction of autophagy because of which there is degradation of cellular proteins and organelles thus accounting for quality control function, ${ }^{6}$ inhibition of N-methyl-D-aspartate receptor-mediated signaling, ${ }^{1,8,10}$ inhibition of glycogen synthase kinase 3, which is a proapoptotic and regulator of inflammation and increases the $\beta$ catenins which is responsible for antiapoptosis of growth hormones. ${ }^{6}$ Lithium is also known to exert its action through brain-derived neurotrophic factor upregulation. ${ }^{11}$ 
Lithium preparations are available mainly as lithium carbonate and lithium citrate as immediate and sustained release with a half-life of 1-2 hrs and 4-5 hrs, respectively. Lithium initially is distributed in the extracellular fluid, gradually gets accumulated in the tissues and does not bind much to plasma proteins with a bioavailability of almost $100 \%$. The concentration of lithium in cerebrospinal fluid is approximately $40-50 \%$ of the concentration in plasma. Lithium is a drug of narrow therapeutic window with a therapeutic range of $0.5-1.3 \mathrm{mEq} / \mathrm{L}$. It is potentially toxic at doses $>1.5 \mathrm{mEq} / \mathrm{L}$. Blood for lithium levels should be drawn just prior to the next dose or at least 6-12 hrs after the last dose. It has been shown in a retrospective study that in recurrent depression, the $12 \mathrm{hrs}$ lithium levels should be between 0.5 and $0.8 \mathrm{mEq} / \mathrm{L}$ and in mania, levels of lithium between 0.9 and 1.4 is necessary for optimal results. ${ }^{8}$

The normal functioning of the thyroid gland is affected by multiple mechanisms of lithium. Lithium gets accumulated in the thyroid gland and inhibits the synthesis and release of thyroid hormones probably by affecting cellular microtubule function. Lithium also alters the thyroglobulin structure and thus affects the function and protein conformation which leads to coupling defects of iodotyrosine. Lithium administration is associated with reduced hepatic de-iodination and clearance of free T4 by decreasing the activity of 1-5'de-iodinase enzyme. Lithium is also known to increase the propensity to thyroid autoimmunity in individuals who are susceptible. ${ }^{9}$ The mechanism by which it exerts its mood stabilizing effects is still not clear. In this study, an attempt to correlate the lithium levels and thyroid function abnormalities associated with it has been made.

\section{Objectives}

- To correlate the lithium levels and thyroid function tests (TFT) in patients of BPAD.

\section{METHODS}

\section{Study design}

\section{Inclusion criteria}

1. Patients clinically diagnosed with BPAD on lithium

2. Patients between 18 and 65 years of age of either sex.

\section{Exclusion criteria}

1. Patients who are previously diagnosed with thyroid dysfunction and on treatment for the same

2. Patients with serious medical disorder endangering life.

\section{Source of data collection}

Data were collected from the Department of Psychiatry, Father Muller Medical College Hospital from patients clinically diagnosed to have BPAD.

\section{Method of collection of data}

- $\quad$ The study was carried out from March 01, 2014 to July 15,2014

- A sample size of 150 was studied

- A written informed consent was taken both from the patient as well as the patient's relatives

- Patients diagnosed with bipolar disorder who did not have a thyroid abnormality or on any drugs which can alter thyroid function at entry were evaluated

- Serum lithium levels estimation was done by Ion selective electrode method in ilyte analyzer and TFT by an electrochemiluminescence method

- Data were analyzed by Karl Pearson correlation coefficient, Chi-square, and standard deviation.

\section{RESULTS}

Correlation of lithium levels and TFT in BPAD patients according to Karl Pearson correlation coefficient was negative with significant $\mathrm{p}<0.002$. Among 150 enrolled candidates, 52 (34.67\%) were females, and 98 (65.4\%) were males. Six patients ( 3 males and 3 females) had thyroid stimulating hormone (TSH) value $<0.27$ with an average lithium value of $1.35 \mathrm{mEq} / \mathrm{L} .6 \%$ nine patients $(5$ males and 4 females) had TSH value $>4.2$ with an average lithium levels of $0.44 \mathrm{mEq} / \mathrm{L} .90 \%$ of the patients with an average lithium level $0.66 \mathrm{mEq} / \mathrm{L}$ had no thyroid function abnormalities.

\section{DISCUSSION}

In our study, we found that at higher serum lithium levels in the therapeutic window the most common thyroid abnormality seen was hyperthyroidism, i.e., at serum lithium level of $1.35 \pm 0.15 \mathrm{mEq} / \mathrm{L}$. Hypothyroidism was common at serum lithium levels of $0.44 \pm 0.12 \mathrm{mEq} / \mathrm{L}$, and the patients with serum lithium values falling in between these values were apparently normal with respect to their thyroid function. T3 and T4 levels were not uniformly distributed because of which we could not correlate their levels with

Table 1: Percentage distribution based on age groups.

\begin{tabular}{|lcc|}
\hline Age distribution & Number of patients & Percentage \\
\hline$\leq 20$ & 8 & 5.34 \\
\hline $20-30$ & 37 & 24.67 \\
\hline $30-40$ & 36 & 24 \\
\hline $40-50$ & 37 & 24.67 \\
\hline $50-60$ & 15 & 10 \\
\hline$\geq 60$ & 17 & 11.34 \\
\hline
\end{tabular}




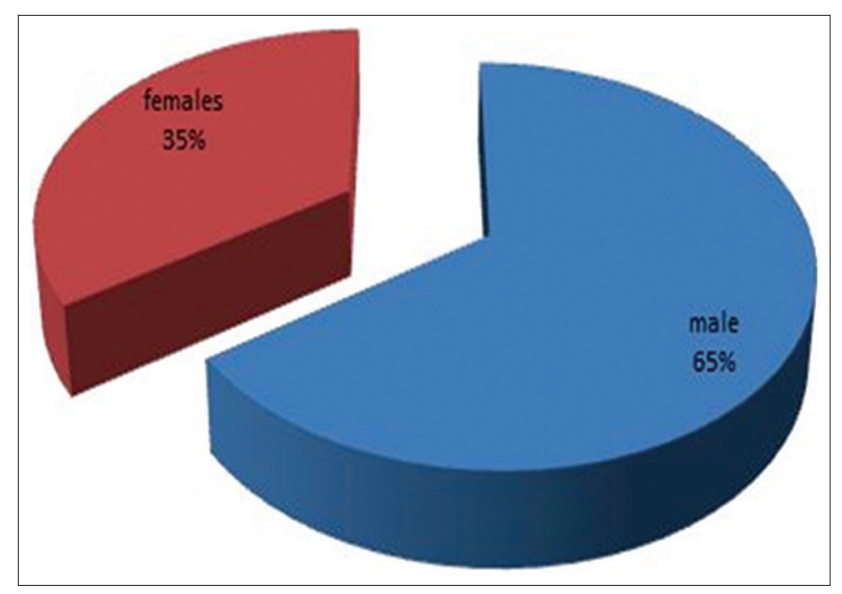

Figure 1: Sex distribution.

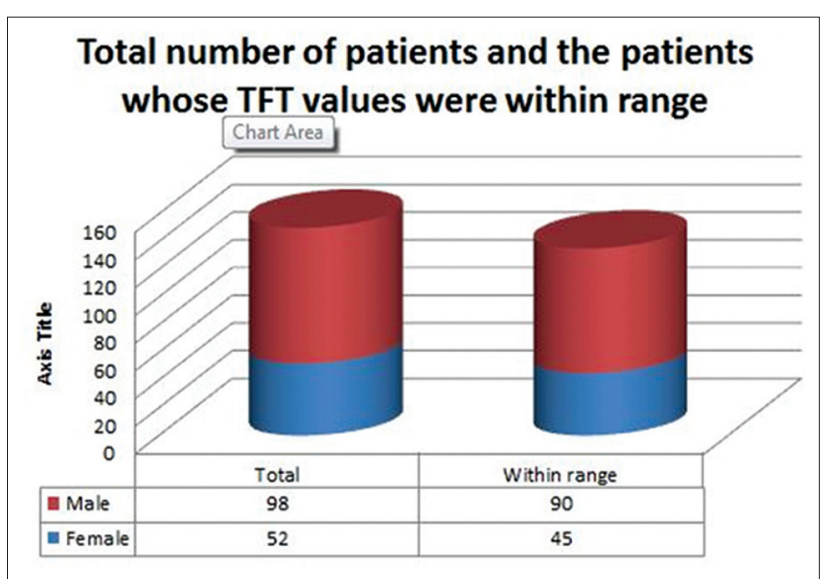

Figure 2: Total number of patients and the patients whose thyroid function test values were within range.

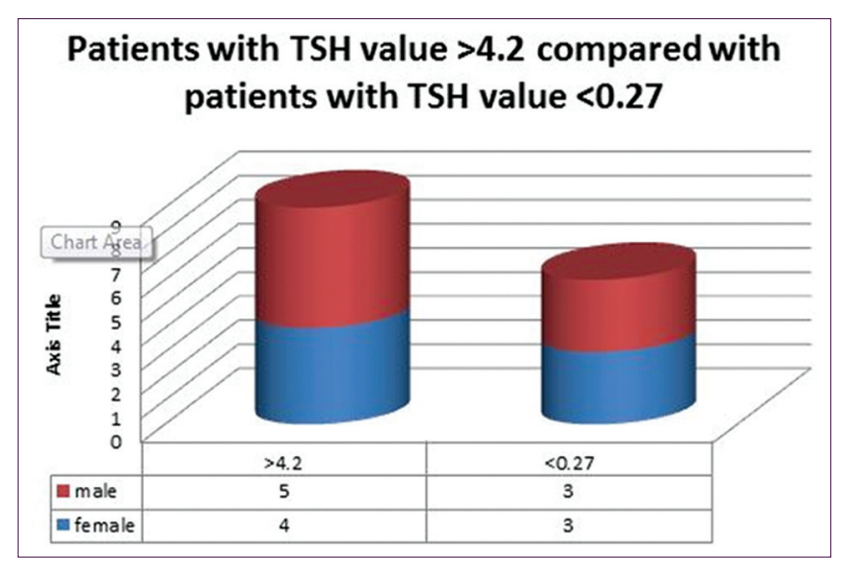

Figure 3: Patients with thyroid stimulating hormone value $>4.2$ compared with patients with thyroid stimulating hormone value $<0.27$.

serum lithium levels.

Perrild et al. and few other studies found that there is no gender difference with regard to thyroid dysfunction. ${ }^{12}$ Several other studies have shown that there is a higher incidence of lithium-induced thyroid abnormality in women ${ }^{13,14}$ which is in agreement with our findings.
In cross-sectional study by Kirov et al., among 115 males and 159 females with affective disorders on long-term lithium therapy in the UK, the prevalence of hypothyroidism was $10.3 \% .^{15}$ Bocchetta et al. in a study among 150 ambulatory Sardinian patients on lithium therapy, no cases of clinical hypothyroidism were found. Subclinical hypothyroidism was noted in $19 \%$ of the patients. Among lithium-treated patients with positive thyroid antibodies, the prevalence of subclinical hypothyroidism increased to $53 \%$. The prevalence of specific anti-thyroid antibodies was positively correlated with age and duration of lithium treatment, and was higher among women. ${ }^{16}$

Bocchetta et al. and Chakrabarti concluded that risk of developing lithium-induced hypothyroidism has been shown to be significantly higher among females, with increasing age ( $>50$ years), presence of family history of thyroid disease and thyroid auto-antibodies. ${ }^{17,18}$

\section{CONCLUSIONS}

Lithium being an effective and pivotal drug in the management of BPAD, concomitant thyroid dysfunction remains an important clinical problem which needs to be addressed. Baseline and regular assessment of TFT, thyroid size using ultrasonography, and measurement of autoantibodies against thyroid peroxidase are recommended among patients prior to and during therapy.

\section{Funding: No funding sources}

Conflict of interest: None declared

Ethical approval: The study was approved by the Institutional Ethics Committee

\section{REFERENCES}

1. Krishnan KR. Psychiatric and medical comorbidities of bipolar disorder. Psychosom Med. 2005;67(1):1-8. Kupfer DJ. The increasing medical burden in bipolar disorder. JAMA. 2005;293(20):2528-30.

2. Kessler RC, Berglund P, Demler O, Jin R, Merikangas KR, Walters EE. Lifetime prevalence and age-of-onset distributions of DSM-IV disorders in the National Comorbidity Survey Replication. Arch Gen Psychiatry. 2005;62(6):593-602.

3. Roberto L. Lithium clearly and directly affects the activity of the thyroid gland in human. Hum Psychopharmacol. 2010;25(7-8):586.

4. Bauer M, Glenn T, Pilhatsch M, Pfennig A, Whybrow PC. Gender differences in thyroid system function: relevance to bipolar disorder and its treatment. Bipolar Disord. 2014;16(1):58-71.

5. Harwood AJ. Lithium and bipolar mood disorder: the inositol-depletion hypothesis revisited. Mol Psychiatry. 2005;10(1):117-26.

6. Motoi Y, Shimada K, Ishiguro K, Hattori N. Lithium and Autophagy. ACS Chem Neurosci. 2014.

7. Croce N, Mathé AA, Gelfo F, Caltagirone C, Bernardini S, Angelucci F. Effects of lithium and valproic acid on BDNF protein and gene expression in an in vitro human 
neuron-like model of degeneration. J Psychopharmacol. 2014;28(10):964-72.

8. Ferier IN, Tyrer SP, Bell AJ. Lithium therapy. Adv Psychiatr Treat. 1995;1:104.

9. Kibirige D, Luzinda K, Ssekitoleko R. Spectrum of lithium induced thyroid abnormalities: a current perspective. Thyroid Res. 2013;6(1):3.

10. Fountoulakis KN. The possible involvement of NMDA glutamate receptor in the etiopathogenesis of bipolar disorder. Curr Pharm Des. 2012;18(12):1605-8.

11. Bauer M, Glenn T, Pilhatsch M, Pfennig A, Whybrow PC. Gender differences in thyroid system function: relevance to bipolar disorder and its treatment. Bipolar Disord. 2014;16(1):58-71.

12. Perrild H, Hegedüs L, Baastrup PC, Kayser L, Kastberg S. Thyroid function and ultrasonically determined thyroid size in patients receiving long-term lithium treatment. Am J Psychiatry. 1990;147(11):1518-21.

13. Cowdry RW, Wehr TA, Zis AP, Goodwin FK. Thyroid abnormalities associated with rapid-cycling bipolar illness. Arch Gen Psychiatry. 1983;40(4):414-20.
14. Yassa R, Saunders A, Nastase C, Camille Y. Lithium-induced thyroid disorders: a prevalence study. J Clin Psychiatry. 1988;49(1):14-6.

15. Kirov G, Tredget J, John R, Owen MJ, Lazarus JH. A crosssectional and a prospective study of thyroid disorders in lithium-treated patients. J Affect Disord. 2005;87(2-3):313-7.

16. Bocchetta A, Bernardi F, Pedditzi M, Loviselli A, Velluzzi F, Martino E, et al. Thyroid abnormalities during lithium treatment. Acta Psychiatr Scand. 1991;83(3):193-8.

17. Bocchetta A, Loviselli A. Lithium treatment and thyroid abnormalities. Clin Pract Epidemiol Ment Health. 2006;2:23.

18. Chakrabarti S. Thyroid functions and bipolar affective disorder. J Thyroid Res. 2011;2011:306367.

doi: $10.5455 / 2319-2003 . i j b c p 20150207$

Cite this article as: Manjuprasad MS, Udaykumar P,

Maitreyee DS, Hegde S. Correlation of serum lithium levels and thyroid function tests in subjects of bipolar affective disorder: a prospective hospital based study. Int J Basic Clin

Pharmacol 2015;4:51-4 